\title{
"You Just Don't See Us": The Influence of Public Schema on Constructions of Sexuality by People with Cerebral Palsy
}

\author{
Tinashe M Dune ${ }^{1}$ \\ ${ }^{1}$ School of Science and Health, University of Western Sydney, Campbelltown, Australia \\ Correspondence: Tinashe M Dune, School of Science and Health, Building 24 Level 4 Room 31, University of \\ Western Sydney, Campbelltown, Australia. Tel: 61-2-4620-3655. E-mail: t.dune@uws.edu.au
}

Received: July 1, 2013 Accepted: July 15, 2013 Online Published: July 16, 2013

doi:10.5430/wjss.v1n1p1 URL: http://dx.doi.org/10.5430/wjss.v1n1p1

\begin{abstract}
This study investigated how people with cerebral palsy (CP) perceived the influence of public sexual schema on their construction of sexuality. In-depth, semi-structured interviews were conducted with five men and two women with moderate to severe cerebral palsy from Australia and Canada. The interview discourse focused on how, if at all, public constructions of sexuality influenced the way in which respondents understood and negotiated their sexuality. Interview data were thematically analyzed using NVivo and manual line-by-line analysis. Findings suggest that people living with CP media to be informative, albeit it skewed in favor of typical others. As such, they perceive themselves to be asexualized by the public media and popular culture. This is highlighted by their absence from media portrayals as desirable sexual partners. They also believed the general public to share popular media's regard of persons with $\mathrm{CP}$ as unlikely sexual partners due to their inability to meet normative expectations of physical movement and functioning. The respondents also believed public perception was linked tothe range ofaccess to services, resources, sexual opportunities and privacy for people with disabilities.Participants preferred typical others as their ideal partners regardless of being disvalued as sexual beings by popular culture and its manifestations. For people with CP inclusion in public presentations of sexuality and intimacy is necessary in order to reinforce people with disabilities as sexual (candidates).
\end{abstract}

Keywords: sexual script theory, sexuality, disability, cerebral palsy, Australia, Canada, sexual agency

\section{Introduction}

Constructions of sexuality by people with cerebral palsy (within contemporary contexts) are informed, in part, by historical constructions of impairment and sexual behavior. For instance, prior to the 20th century sexual activity for pleasure had been ignored, vilified and undermined through segregation, institutionalization and eugenics (Ross \& Rapp, 1981). As such, the acceptance and representation of sexuality for people with disabilities was largely absent. Constructing sexuality and disability in this way continues within contemporary settings and include a number of public factors worthy of especial consideration.

Open discourse about the public factors which influence constructions of sexuality for people with disabilities brings awareness of the barriers which may inhibit sexual participation and prompt awareness and understanding. In doing so, sexual expression, pleasure, intimacy and ultimately satisfaction are acknowledged as essential to the formation of inclusive public constructions of disability. As such, this paper qualitatively explores public factors and public sexual schema which may influence contemporary constructions of sexuality and disability for people with cerebral palsy.

\subsection{Public Factors}

For people with disabilities the relationship between impairment and the construction of their own sexuality is mediated by socio-cultural attitudes about disability and expectations of sexual activity. For example, the myth that people with disabilities are asexual or incapable of sexual expression is a widespread myth which disables socio-sexual access and opportunities for people in this group (i.e. Brown, 1988; Chance, 2002; Dune \& Shuttleworth, 2009; Earle, 1999; Joseph, 1991; Sanders, 2007; Stevens, Steele, Jutai, Kalnins, Bortolussi \& Biggar, 1996; Taleporos \& McCabe, 2005; Wiwanitkit, 2008; Xenakis \& Goldberg, 2010). Many of the misconceptions about sexuality and disability can be attributed to a lack of clarity, representation and education about people with 
disabilities and their sexualities. Based on contemporary literature (see above) which explored disability and sexuality the following themes have been indicated as important to constructions of sexuality in people with disability:

- The myth of disability and asexuality

- Contemporary media and popular culture

- Normative movement and functioning

- Lack of accessibility

- Lack of privacy

\subsubsection{The Myth of Disability and Asexuality}

While alternate constructions of disability and sexuality exist, the erroneous construction of people with disabilities as asexual is increasingly recognized as an important influence in how sexuality within this population is constructed (i.e., Majiet, 1996; McCabe \&Taleporos, 2003; Milligan \&Neufeldt, 2001; Shakespeare, 2000; Shuttleworth, 2000). This public misperception of disability and sexuality is what Milligan and Neufeldt (2001), among others, call the 'Myth of Asexuality' which encompasses two lines of thinking depending on whether the person's impairments are physical or intellectual;

First, for people with physical disabilities, because of actual or presumed sexual dysfunction, gratification opportunities are considered so limited that sexual needs are either deemed to be absent or subjugated. Second, although their sexual function is typically intact, individuals with intellectual disabilities and/or psychiatric disorders are thought to have limited social judgment, and therefore, lack the capacity to engage in responsible sexual relationships (p. 92).

Here mental disability is defined as "any disability or disorder of the mind or brainwhether permanent or temporary which results in a disturbanceor impairment of mental functioning" (Law Commission, 1995,p. 36). Whereas physical disability is defined as a condition where a person experiences significant deviation or loss in their body function or structure that results in limitations in the physical activity (World Health Organization, 2011). The eugenics movement in North America, for example, was particularly aimed at eliminating such disabilities. However, little differentiation was made between mental and physical disability and the social privileges and human rights these individuals were entitled to. This lack of differentiation between mental and physical disability is maintained and portrayed in contemporary contexts (i.e., media and popular culture) through condescending and paternalistic behaviour exhibited towards people with disabilities.

\subsubsection{Contemporary Media}

The media acts a public influence on the expression of sexuality.In the past few decades, particularly with the advent of the World Wide Web, media have penetrated almost every aspect of social life, particularly in developed societies. At school young children discuss the most recent adventure of their favorite superhero(ine) and act out the script from the last episode when they play with their peers. Adolescents talk about the newest and hottest pop singer whose concert was aired the night before and as they leave school they sing and dance (in unison) their favorite tune. Adults congregate around the proverbial water cooler and chat about the 'pod-cast' of their favorite sit-com or soap opera. Baudrillard (1983) argued that one of the consequences of the extent of media infiltration in contemporary life has to do with hyperreality. Hyperreality is experienced when media consumers cannot distinguish between reality and the simulated images used in, advertizing, movies, television shows or pornography. Therefore, a considerable part of how disability (and sexuality) is conceptualised has to do with "the ubiquitous presence of the media in our everyday lives [which] has contributed to its potency as an important influence on attitude formation" (Milligan \& Neufeldt, 2001, p. 37).

Within popular Western media, for example, satisfying sexual encounters, desirable sexual partners, appropriate expressions of sexuality and constructions of sexuality are portrayed as biologically, physically and economically determined (Hung, 2010). By excluding representations of people who do not fulfill the media's target population demographics sex as an act of pleasure and reproduction is reserved for the "best" human specimens. Subsequently, people with disabilities are viewed as unacceptable candidates for reproduction or even capable of engaging in sexual activity for their own pleasure as well as that of potential partners.

The sexual scripts portrayed in the media as "normal" and "appropriate" minimise the actual spectrum of human experience and instead focuses on ideals of perfection. As such, the media has a great influence on the representation of people with disabilities (Goggin \& Newell, 2002). Media portrayals of what is sexy or desirable have seen significant changes since the 1950's (i.e., Glee, 2010; Jersey Shore, 2010; Pumpkin, 2002; Transformers; 2007). 
However, contemporary popular culture continues to represent people with various illnesses or impairments who are sexually marginalized as undesirables, deviants or excluded from portrayals of sexuality altogether (i.e., Jersey Shore, 2010; Tepper, 1999; 2000; The Hard Times of RJ Berger, 2010).

\subsubsection{Expectations of Normative Movement and Functioning}

Expectations of normative bodily functioning affect both people with disabilities and typical others. A participant in Taleporos and McCabe's (2001) study jokingly explained: "Yeah, it's really hard because guys expect you to be able to get into 101 different positions and I'm lucky if I can get into three!" (p. 137). Due to physical restrictions some people with physical disabilities deal with they may find it difficult to move their limbs, may have issues with trunk control, issues with spasticity or moving without pain. Also, there are many individuals who use devices to assist them in activities of daily life, which can become barriers to sexual negotiation: "When dealing with sexual expression there is only so much you can do in a wheelchair" (Taleporos\& McCabe, 2001 p. 137).

Shuttleworth (2000) explained that "in a culture that emphasizes sex acts and performance, men and women [with disabilities] are often portrayed as axiomatically prohibited from participation in satisfying sexual relationships and destined to emotionally empty lives" (p. 95). Shuttleworth (2000) explored the accounts of the search for sexual intimacy for 14 men with CerebralPalsy which revealed a range of impediments, issues "and a complex intersubjective process(es) in their search for a lover" (p. 263). He discussed the social expectations of normative functioning and control which the majority of the men in his study expressed as a cause for frustration in their efforts to negotiate sexual relationships. Some of the men in the study felt that the impairment often physically disqualified them from social and sexual interactions. Shuttleworth explained that "those who used wheelchairs often put it in terms of women being turned off by the fact that they were in a wheelchair" (p. 267).

The physical barrier of not being able to move in a way that society expects the body to move may affect how a person with Cerebral Palsy or other physical impairment relates to others and themselves based on their body. Thus, expectations of normative movement and functioning are factors in the disablement of a person's chances to be considered as a sexual partner. In addition, there are structural barriers to the access of built environments that deprive people with disabilities of the same number of opportunities to interact with others as their peers, and can thus restrict access to sexual relationships.

\subsubsection{Lack of Accessibility}

Access has an important socio-structural influence on sexual participation (Barnes \& Mercer, 2010; Corker \& French, 1999; Corker \& Shakespeare, 2002; Oliver, 1996). Socio-structural access is characterized by the relationship between environmental infrastructure and social opportunities and ultimately mediates access to social opportunities and sexual information.

Access to social opportunities may be limited for some people with disabilities due to infrastructure which does not facilitate easy access to built structures such as social venues (Corker \& French 1999; Corker \& Shakespeare 2002). Limited socio-structural access may thus exacerbate the social expectation of normative movement and functioning which some people with disabilities encounter daily (Schillmeier, 2007). For example, appropriate ramps, wide walkways, large enough bathroom facilities that can accommodate wheelchairs or Hoyer lifts, appropriate elevators, automatic doors and accessible buttons with which people can operate these devices continue to be absent or difficult to operate in modern environments (Pendo, 2010). In addition, many of the places people commonly frequent to meet new people, and therefore negotiate sexual relationships, are not accessible, people with disabilities who rely on wheelchairs or who find it especially difficult to go up a flight of stairs, and are at a distinct disadvantage.

Lack of accessibility may be a symptom of a bigger social problem in which people with disabilities are excluded from opportunities for social and sexual interaction. As the provision of social opportunities is often a precursor for sexual opportunities the lack of resources to include and integrate disability may very well be the most restrictive barrier to sexual inclusion. Social and sexual integration however, can be supported through unrestricted access to education and information about disability.

Often the barriers to sexual activity and relationships that people with physical disabilities experience are the result or ignorance caused by a collective lack of education and information. For example, Anderson and Kitchin (2000) examined access to family planning clinics for people with disabilities and reported that facilities for sexual health education and relationship information were not adequately informative or accessible. Accessible and relevant information and education for young people and adults with disabilities promotes their right to intimacy and relationships and can facilitate a more accepting and inclusive social environment (i.e., Esibill, 1980; Rousso, 1993; Berman, Harris, Enright, Gilpin, Cathers \& Bukovy, 1999; Earle, 1999; Murphy, Molnar \& Lankasky, 2000). However, research on what people with disabilities formally know about or have been formally educated about sex, 
sexual activities, sexual health, contraceptives, sexual intimacy and relationships, their sexual rights and sexual agency is meager. Information designed to foster sexual knowledge, positive sexual identity and sexual agency is vital for people with disabilities in order to promote self-respect, pleasure, and safety.

\subsubsection{Lack of Privacy}

Personal care is often a part of life for people with moderate to severe disabilities (Winkler, Sloan \& Callaway, 2007). According to ParaQuad (2010), paraplegic and quadriplegic association of New South Wales, Australia, personal or attendant care is defined as home-based support and plays a vital role in the lives of people with high level physical disabilities by supporting them to: maintain active lifestyles, achieve independence and dignity and have control over their lives.

Due to personal care requirements that can often be quite intimate (bowel and urine voiding regimens) it can be difficult to maintain privacy which can be necessary to express one's sexuality. Crewe (1979), who discussed the psychologist's role in sexual rehabilitations for people with disabilities, emphasised that there are many people with physical disabilities that require daily, and some even hourly personal care so being able to find time and space for privacy is difficult. During the author's time working as a personal care assistant for students (most of whom had Cerebral Palsy) who attended university in Ottawa, Ontario, Canada, clients indicated that in certain other facilities in which they lived, the residents were not permitted to lock their doors and in some cases even to close them. Although it seems that these types of rules are enforced so that personal care attendants or emergency services can reach the client in the event that they were in trouble this lack of privacy makes sexual expression particularly difficult. Thus, rules against something as simple as door-closing or locking can inadvertently reinforce the myth that people with physical disabilities do not have a need for privacy and sexual expression (Crewe, 1979).

\subsection{Public Sexual Schema}

These historical and contemporary constructions of sexuality and disability form the basis for public sexual schema which define how and with whom individuals should engage with sexually. Public sexual schemas, also known as public sexual scripts, are created, influenced and reinforced by attitudes and interpretations presented in popular culture and media (Simon \& Gagnon, 1986, 1987, 2003). As such, people may be encouraged to engage in sexual activity only with those who are publically prescribed as appropriate (Simon \& Gagnon, 1986). The public construction of who is an appropriate sexual partner often excludes individuals with disabilities and their experiences of sexuality (Guildin, 2000). If people with disabilities are publically (i.e., mass media) excluded from portrayals of sexuality they may not being considered as viable sexual partners and thus experience reduced sexual opportunities and social access (Overstreet, 2008). Due to the pervasiveness of public sexual schema which excludes people with cerebral palsy (or other disabilities) understanding the salience and influence of these schemas is of interest. This research builds on understandings of public sexual schema by allowing people with cerebral palsy to describe the influence (if at all) of the factors which make up sexual schema on their constructions of their sexuality.

\section{Methods}

This paper presents an excerpt of results from a doctoral research project which employed a hermeneutic phenomenological approach to investigate the salience of sexual scripts (public, interactional and private) in constructions of sexuality by people with cerebral palsy. An in-depth, semi-structured interview guide was used for data collection and comprised of the following sections: demographics and severity of disability, private sexual scripts, interactional sexual scripts, public sexual scripts and reflective summary. Interviews were conducted via email, telephone and/or face-to-face (based on participant preference).

In the public sexual scripts section of the interview participants were asked questions which aimed to gather information about the affect public sexual scripts had on constructions of sexuality as experienced by people with Cerebral Palsy. To understand how people with Cerebral Palsy were taught to construct (their) sexuality they were asked; "Where did you learn about sex? What did you learn about sex?" Further, participants were asked to reflect on their conceptualization and opinion about the term sexual spontaneity in order to ascertain whether people with Cerebral Palsy described their sexuality as inclusive of popular constructions of sexual spontaneity; "How would you define or explain the term sexual spontaneity?" and "How does your explanation of sexual spontaneity fit into your sexuality?". In addition, participants were asked to describe their perception of romance ("What is your idea of romance?") and satisfying sexual experiences ("What factors have influenced how you experience your sexuality?"). These questions were used to identify any aspects of sexual spontaneity within individual experiences of sexuality as well as gain information about the participant's perception of what their sexual partner would be like and/or look like. The data were analyzed for content by identifying topics and substantive categories within participants' accounts in relation to the study's objectives. 


\section{Sample and Participant Recruitment}

This study included seven participants; five men and two women. Four of the participants were from Australia and three from Canada (see Table 1). The study recruited from Canada and Australia in order to enhance the possibility of finding members of the target population to participate.

In Australia, participants were recruited through advertisements published in community newspapers, bulletins, through advocacy group and sexuality and/or disability focused newsletters and webpages. In addition, the snowballing technique was carried out at the end of participant interviews and required asking each participant if they knew someone who met the eligibility criteria and, if so, whether s/he would be willing to give that person a copy of the participant information sheet. The author did not know the identity of this person, and the interviewee did not know if that person agreed to participate in the project or not.

In Canada, participants were sought through the Attendant Care Program in Ottawa, Ontario, Canada. The Attendant Care Program services two of the major educational institutions in the city with round-the-clock provision of personal care for tertiary students with disabilities who live in the university residence buildings. The program which has been running for over 20 years services approximately $50-60$ students per year with numbers increasing every year. Due to the client-directed style of the program clients are provided with the resources they need to live independently through the provision of dignity-focused care and accessible living arrangements. As the author was formerly employed by the service she forwarded the coordinator of the program the details of this project and was informally given permission to ask clients (the majority of whom had Cerebral Palsy) of the Attendant Care Program if they would like to participate.

The data were analyzed for content by identifying topics and substantive categories within participants' accounts in relation to the study's objectives. In addition, NVivo was used to ascertain topical responses and emergent substantive categories, coding particularly for word repetition, direct and emotional statements and discourse markers including intensifiers, connectives and evaluative clauses. Due to the rich and contextual nature of the data, participant's responses have been presented in their conceptual entirety.

Table 1. Participant summary

\begin{tabular}{|c|c|c|c|c|c|c|c|}
\hline $\begin{array}{l}\text { Participant } \\
\text { (Pseudonym) }\end{array}$ & Sex & $\begin{array}{l}\text { Type of Cerebral } \\
\text { Palsy }\end{array}$ & $\begin{array}{l}\text { Assistive Devices or } \\
\text { Services }\end{array}$ & $\begin{array}{l}\text { Socio-economic } \\
\text { Status, education } \\
\text { and ethnicity }\end{array}$ & Medical Interventions & $\begin{array}{l}\text { Living } \\
\text { Arrangements }\end{array}$ & Sexual Profile \\
\hline John & Male & $\begin{array}{l}\text { Spastic } \\
\text { Quadriplegic } \\
\text { Cerebral Palsy } \\
\text { (severe) }\end{array}$ & $\begin{array}{l}\text { Mechanized } \\
\text { wheelchair, daily } \\
\text { personal assistance } \\
\text { from others }\end{array}$ & $\begin{array}{l}\text { Upper-middle class, } \\
\text { tertiary education, } \\
\text { Caucasian } \\
\text { Australian }\end{array}$ & $\begin{array}{l}\text { Major musculoskeletal } \\
\text { surgery during childhood } \\
\text { and adolescence. } \\
\text { Rehabilitative } \\
\text { maintenance. }\end{array}$ & $\begin{array}{l}\text { Lived with his } \\
\text { mother in his } \\
\text { family's home }\end{array}$ & $\begin{array}{l}\text { Heterosexual, } \\
\text { sexually active, no } \\
\text { history of long term } \\
\text { sexually intimate } \\
\text { relationships }\end{array}$ \\
\hline Mary & Female & $\begin{array}{l}\text { Spastic } \\
\text { Paraplegic } \\
\text { Cerebral Palsy } \\
\text { (moderate) }\end{array}$ & $\begin{array}{l}\text { Occasional use of } \\
\text { crutches }\end{array}$ & $\begin{array}{l}\text { Middle class, } \\
\text { tertiary education, } \\
\text { Caucasian } \\
\text { Australian }\end{array}$ & $\begin{array}{l}\text { Major musculoskeletal } \\
\text { surgery during childhood } \\
\text { and adolescence. } \\
\text { Rehabilitative } \\
\text { maintenance. }\end{array}$ & $\begin{array}{l}\text { Lived independently } \\
\text { in an apartment with } \\
\text { her partner }\end{array}$ & $\begin{array}{l}\text { Heterosexual, in a } \\
\text { long term sexual } \\
\text { relationship at time } \\
\text { of interview }\end{array}$ \\
\hline Brian & Male & $\begin{array}{l}\text { Ataxic } \\
\text { Quadriplegic } \\
\text { Cerebral Palsy } \\
\text { (severe) }\end{array}$ & $\begin{array}{l}\text { Mechanized } \\
\text { wheelchair, daily } \\
\text { personal assistance } \\
\text { from others }\end{array}$ & $\begin{array}{l}\text { Middle class, } \\
\text { tertiary education, } \\
\text { Caucasian } \\
\text { Australian }\end{array}$ & $\begin{array}{l}\text { Major musculoskeletal } \\
\text { surgery during childhood } \\
\text { and adolescence. } \\
\text { Rehabilitative } \\
\text { maintenance. }\end{array}$ & $\begin{array}{l}\text { Lived in an } \\
\text { independent living } \\
\text { facility }\end{array}$ & $\begin{array}{l}\text { Heterosexual, } \\
\text { sexually active, no } \\
\text { history of long term } \\
\text { sexually intimate } \\
\text { relationships }\end{array}$ \\
\hline Leah & Female & $\begin{array}{l}\text { Spastic } \\
\text { Paraplegic } \\
\text { Cerebral Palsy } \\
\text { (moderate) }\end{array}$ & $\begin{array}{l}\text { Mechanized } \\
\text { wheelchair, daily } \\
\text { personal assistance } \\
\text { from others }\end{array}$ & $\begin{array}{l}\text { Lower-middle class, } \\
\text { tertiary education, } \\
\text { Caucasian } \\
\text { Australian }\end{array}$ & $\begin{array}{l}\text { Major musculoskeletal } \\
\text { surgery during childhood } \\
\text { and adolescence. } \\
\text { Rehabilitative } \\
\text { maintenance. }\end{array}$ & $\begin{array}{l}\text { Lived in an } \\
\text { apartment with her } \\
\text { boyfriend. }\end{array}$ & $\begin{array}{l}\text { Heterosexual, in a } \\
\text { long term sexual } \\
\text { relationship at time } \\
\text { of interview }\end{array}$ \\
\hline Ian & Male & $\begin{array}{l}\text { Ataxic } \\
\text { Quadriplegic } \\
\text { Cerebral Palsy } \\
\text { (severe) }\end{array}$ & $\begin{array}{l}\text { Mechanized } \\
\text { wheelchair, daily } \\
\text { personal assistance } \\
\text { from others }\end{array}$ & $\begin{array}{l}\text { Lower-middle class, } \\
\text { tertiary education, } \\
\text { Caucasian Canadian }\end{array}$ & $\begin{array}{l}\text { Major musculoskeletal } \\
\text { surgery during childhood } \\
\text { and adolescence. } \\
\text { Rehabilitative } \\
\text { maintenance. }\end{array}$ & $\begin{array}{l}\text { Lived in an } \\
\text { independent living } \\
\text { facility. }\end{array}$ & $\begin{array}{l}\text { Heterosexual, } \\
\text { sexually active, no } \\
\text { history of long term } \\
\text { sexually intimate } \\
\text { relationships }\end{array}$ \\
\hline Trevor & Male & $\begin{array}{l}\text { Spastic } \\
\text { Quadriplegic } \\
\text { Cerebral Palsy } \\
\text { (severe) }\end{array}$ & $\begin{array}{l}\text { Mechanized } \\
\text { wheelchair, daily } \\
\text { personal assistance } \\
\text { from others }\end{array}$ & $\begin{array}{l}\text { Upper-middle class, } \\
\text { tertiary education, } \\
\text { Caucasian Canadian }\end{array}$ & $\begin{array}{l}\text { Major musculoskeletal } \\
\text { surgery during childhood } \\
\text { and adolescence. } \\
\text { Rehabilitative } \\
\text { maintenance. }\end{array}$ & $\begin{array}{l}\text { Lived in an } \\
\text { independent living } \\
\text { facility }\end{array}$ & $\begin{array}{l}\text { Heterosexual, in a } \\
\text { long term sexually } \\
\text { intimate } \\
\text { relationship at time } \\
\text { of the interview }\end{array}$ \\
\hline Alex & Male & $\begin{array}{l}\text { Spastic } \\
\text { Quadriplegic } \\
\text { Cerebral Palsy } \\
\text { (severe) }\end{array}$ & $\begin{array}{l}\text { Mechanized } \\
\text { wheelchair, daily } \\
\text { personal assistance } \\
\text { from others }\end{array}$ & $\begin{array}{l}\text { Upper-middle class, } \\
\text { tertiary education, } \\
\text { Caucasian Canadian }\end{array}$ & $\begin{array}{l}\text { Major musculoskeletal } \\
\text { surgery during childhood } \\
\text { and adolescence. } \\
\text { Rehabilitative } \\
\text { maintenance. }\end{array}$ & $\begin{array}{l}\text { Lived in an } \\
\text { independent living } \\
\text { facility }\end{array}$ & $\begin{array}{l}\text { Homosexual, high } \\
\text { frequency of casual } \\
\text { sexual encounters, } \\
\text { no history of long } \\
\text { term sexually } \\
\text { intimate } \\
\text { relationships }\end{array}$ \\
\hline
\end{tabular}




\section{Results and Discussion}

Four sub-themes characterized the perceived influence of Public sexual schema on participant sexuality: 1) Contemporary Media and Popular Culture, 2) The Myth of Disability and Asexuality, 3) Expectations of Normative Movement and Functioning and, 4) Issues of Accessibility.

\subsection{Contemporary Media and Popular Culture}

Primarily, participants expressed that media (although skewed) was a source for sexual information. Of equal importance was the impact of public sexual scripts. Of these scripts respondents noted that normative gender role expectations influenced how they constructed their sexuality. As such, Contemporary Media and Popular Culture (see Figure 1) included three sub-themes: Media as a Source for Sexual Information, The Impact of Public Sexual Scripts and Constructions of Masculinity and/or Femininity.

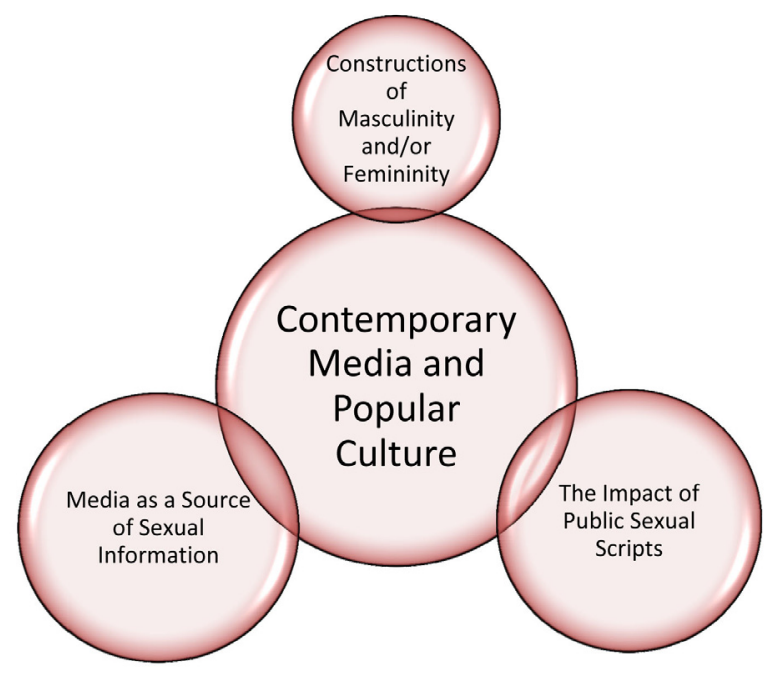

Figure 1. Contemporary Media and Popular Culture Theme and Sub-themes

(The size of each bubble represents its relative salience within the main theme.)

\subsubsection{Media as a Source for Sexual Information}

Participant responses indicate that contemporary media served as a source for sexual information. The data indicate two conceptualizations about sexual information which participants acquired from the media; 1) how to experience, conceptualize and construct sexual behaviour (see also Sanders, 2008) and, 2) sexual information from media as skewed and/or unrealistic (see also Brown, Halpern \&L'Engle, 2005). Responses from Alex, Ian and Trevor indicated that contemporary media has informed how they experience, conceptualize and construct sexual behaviour.

Alex: I learned about sex and what to do from the media. I was watching pornography from when I was 12 .

Ian: From TV, movies, from media I learnt what to do? How to do it? From pornography I thought 'oh ya that's how it's done'.

Trevor: I learned that sexuality and sex was an expression of intimacy between two (or more) partners for the purposes of enjoyment. I learned the mechanics of sex, through sex education classes in school. I learned some of my own sexual barriers and desires, as well as what excites me. As a consumer of media, I learned a lot from television, although I recognized from an early age that a lot of it was a skewed reality.

Although all participants indicated that contemporary media and popular culture were sources of information, Trevor and John notably described the information as skewed or unrealistic. For John the process of learning about sexual experiences from the media was implicit but he ultimately thought of it as inaccurate.

John: You learn it by osmosis if the truth be told and you don't have to go far to find, it's all over the newspapers, all over the internet. And I'm sort of matter a fact about it now that it doesn't even raise an eyebrow. It doesn't matter anymore. I mean particularly with the internet. Everyone knows everything and everybody's seen just about everything. And you know, you can go back to the media, a lot of stars became very famous simply because they had some sort of extra, sexual exploit recorded on tape. And that tape ended up somewhere and 
somebody publicized it or gave it to a media outlet or put it online. I guess with my interest in media, current affairs and popular culture sexual information is always there whether in a polite or, most often, blunt way...Equally though, I know it's not accurate either.

Through the intake (whether active or passive) of sexualized messages (accurate or otherwise) from contemporary media and popular culture, participants perceived public sexual scripts to have impressed upon them idealized portrayals of sexuality and disability.

\subsubsection{The Impact of Public Sexual Scripts}

The impact of contemporary media and popular culture can be seen in participant's reiteration of popular public scripts about people with disabilities and their experiences of sexuality. Several types of impact described by participants included; 1) the impact categorizations of disability in the media and popular culture have on socio-sexual inclusion (see also Hartnett, 2000), 2) the impact of representations of sexuality which lack inclusion of disability (see also Raynor\& Hayward, 2009), 3) portrayals of disability which deny social and sexual agency (see also Duncan, Goggin\& Newell, 2010) and, 4) public sexual scripts as the instigator of upward and downward social comparison (see also Hammer, Ozolins, Idvall, \& Rudebeck, 2009). For instance, Brian and Alex explained that the ways in which disability is constructed and categorized by media made it difficult to be noticed.

Brian: One of my annoyances about the media is that disability tends to be constructed in two extremes. One is that we're terribly vulnerable or needy and totally reliable on a carer (which holds a kernel of truth) or we exist as mountain climbers or paralympians conquering the world. And there is no middle ground but $99.99 \%$ of us live in this gray-area-middle-ground and you just don't see us.

Alex: I guess my idea [of romance] comes from media depictions and what I see played out at bars, but I have no real life experience to draw from. I honestly feel that romance is only in the movies and that because I am 'different', I will not find it conventionally or long term.

According to Brian and Alex representations of sexuality and disability in the media may lack inclusivity. As such, participants felt that exclusive representations of sexuality and disability in the media restricted access to sexual opportunities. For instance, Leah and Mary felt that exclusive constructions of sexuality implied that they were socially and sexually inadequate.

Leah: And then when you've got someone who-the messages they are getting is that you're not sexually attractive, you're not going to get anyone to do that [have sex with you]. You're not going to have someone who is going to love you outside of your family. Because I think that's what a lot of people get because then it's going to affect your social development.

Mary: Yeah... because part of me, I am a bit of a romantic and I think I like the idea of just that one person, but it's not always true or realistic. But thank goodness considering the amount of things I was willing to change in myself to try and make friends with people but doing that was not one of them. Because I could have [had sex] and I came close a couple of times.

Leah and Mary made an effort to conceptualize the salience of public sexual scripts within the construction of their sexuality. John however, felt that media portrayals and discourse about impairment denied people with disabilities the right to sexuality. For instance, John explains that portrayals of disability within the media and disability advocacy groups exclude people with disabilities from experiences of sexuality and agency:

John: I suggest for example you look at some of the debates...in the media, as to what you do with a severely mentally handicapped person...And they are getting to the age that they'll have a period or something like that so it's probably best, to remove the sexual organs or turn them off in such a way so that a person won't have those 'difficulties' because they won't understand what's going on. For my own part I take the view that it's actually quite a reasonable step to take when you are dealing with a person who is that disabled. And they can't deal with those sorts of problems. But there's a disability lobby that says 'how dare you?'

Based on John's thoughts discussions of sexuality in the media and advocacy groups seem exclusionary. However, Ian felt that public sexual scripts had a more balanced (neither wholly positive nor wholly negative) impact on the construction of his sexuality. As such, the construction of his sexuality involved both upward and downward social comparison. Ian explained:

Ian: Mass media and the sexually charged culture that we live in have also played a role in influencing my sexuality, both in the positive and negative. Positive because it has allowed me to place my sexuality in the context of the larger world, and has slowly helped me build up my sexual confidence. In the negative, because it 
has at times, made it seem as though I need to look a certain way, or perform a certain act in order to be sexually desirable.

In this regard, Ian highlights the difficulty some people with Cerebral Palsy may have in the effort to feel positive about their sexuality while conforming to a variety of public sexual scripts. In particular, the implication of public ideals of masculinity or femininity as presented by contemporary media and popular culture was difficult to incorporate into the construction of participant's sexuality.

\subsubsection{Constructions of Masculinity and/or Femininity}

Contemporary media and popular culture produce many public sexual scripts which influence human sexuality (see also Brown, Halpern \& L'Engle, 2005). The participants believed that conforming to normative constructions of masculinity and femininity, as portrayed by the media, influenced the construction of their sexuality. Two issues were of relevance; 1) the traits a perfect male or female would have (see also Lemish, 2010) and, 2) acceptable and attractive female and male attributes and behaviours (see also Jackson, 2005; Dune \& Shuttleworth, 2009). Mary and Alex's description of "the" sexually attractive woman and man exemplifies this sentiment.

Mary: When you think of attractive people...They're the woman most women would hate, because they're perfect. The type of people who are good-looking, confident and self-assured. They would just be able to put everybody at ease and there's something indefinably sexy about them. That's what I find sexy.

Alex: I always knew that I was 'different' from other kids my age. I always found myself attracted to men. I had crushes on masculine TV characters (John Stamos aka Uncle Jesse from Full House). I liked how masculine he was in that role. I found myself attracted to that type even when I was young.

Although Mary indicated that the ideal of the "perfect man or woman" was sexy she could comprehensively define why. From a young age Alex internalized portrayals of masculinity from popular television shows which influenced the "type" of man he presently finds attractive. Leah however, perceived the normative construction of the perfect man as more difficult for males to deal with than the normative construction of the perfect woman for females.

Leah: I often wonder what it would be like to be a guy with CP because as a girl who is meant to be dainty and delicate and, you know, somewhat helpless for men, there's some ability for people to reconcile that with your physical weakness because you're a girl anyway.

On the one hand, Leah explained that her perception of the hegemonic construction of femininity involved women as dainty, delicate and helpless. On the other hand, the men in this study indicated that part of their attempts to fulfill hegemonic constructions of masculinity involved conforming to what they were, or who they were supposed to find attractive. John's attraction to a popular female television personality exemplifies his acceptance of hegemonic constructions of femininity.

John: I think as a male you always maintain a certain amount of whatever the hormones... which means you should respond positively when people or certain sights appear. Like, Jennifer Hawkins...I'm the same sort of red-blooded male...for any pretty face that smiles at you, particularly if they're long legged and absolutely gorgeous...To add to the mixer being hot for someone like that is really the first time you fall in love although you don't really know it.

Being attracted to the type of women that contemporary media validates as attractive contributed to how John constructed his idea of the ideal sexual partner. However, his thoughts imply, through upward social comparison (see also Hammer, Ozolins, Idvall, \& Rudebeck, 2009), that he would never be considered in return. Brian explained that proving oneself as a sexual contender is compromised by having a disability while at the same time trying to conform to hegemonic constructions of masculinity.

Brian: Men have to do it and initiate. They can't get in there if they don't perform and ask the lady out and get things going. How are dudes expected to be negotiating sexual relationships when they have CP?

Brian's sentiments raise the important issue of incorporating one's sexuality with experiences of disability in an effort to consolidate one's identity. However, five participants indicated that positive constructions of sexuality, while living with Cerebral Palsy, were often undermined by the myth of disability and asexuality.

\subsection{The Myth of Disability and Asexuality}

The data suggest that all the participant's constructions of their own sexuality were influenced by the pervasive myth that people with disabilities are not sexual beings. In this regard, five participants were concerned about the erroneous nature of the myth and how it affected the way that others perceived them. Four participants seemed to 
have internalized elements of the myth of disability and asexuality. In addition they implied that asexuality was inevitable due to the pervasive nature of the myth. As such, participant data fell into two sub-themes (see Figure 2): Perceptions of How Others Perceive Disability and Sexuality and Internalization of the Myth of Disability and Asexuality.

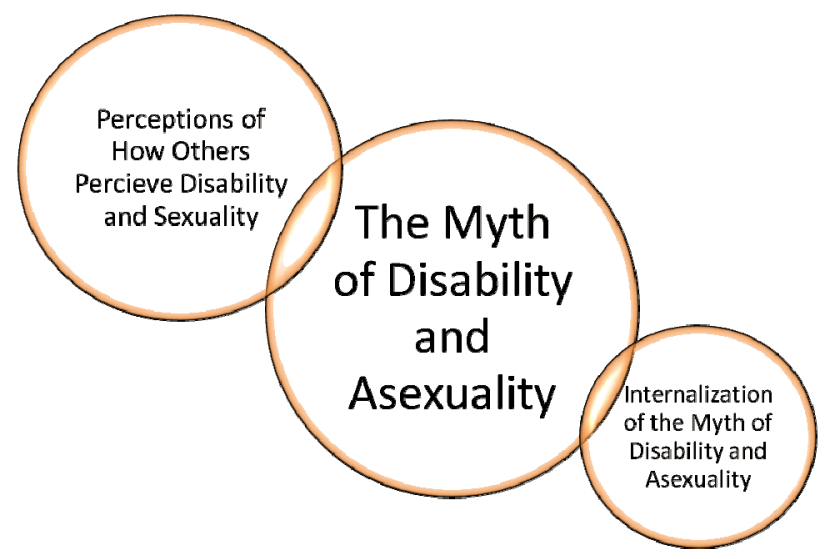

Figure 2. The Myth of Disability and Asexuality Theme and Sub-themes

\subsubsection{Perceptions of How Others Perceive Disability and Sexuality}

Respondents indicated that they had several concerns about how others perceived disability and sexuality. Notably participants articulated that public schema reinforced; 1) the erroneous perception that people with disabilities were inherently asexual (see also Milligan \&Neufeldt, 2001), 2) people with disabilities are destined to sexual dissatisfaction (see also McCabe \&Taleporos, 2003), 3) others' perceptions of disability and sexuality as detrimental to socio-sexual development (see also Dune, 2012a), 4) the presumption that people with physical disabilities also have mental disabilities (see also Milligan \&Neufeldt, 2001) and 5) the salience of a lack of public knowledge about sexuality and disability (see also Cole \& Cole, 1993; see also Shakespeare, 2000). Trevor and Ian for example, explained how the erroneous perception from others that people with disabilities were inherently asexual manifested in their lives:

Trevor: I think that I am overlooked and not necessarily considered as a sexual partner.

Ian: As I say, I do not think that most able-bodied people will necessarily see disabled people as sexual. I think most people will remain to be quite disturbed with that concept.

The myth of disability and asexuality in this context implies that people with disabilities are destined to sexual dissatisfaction; destined to a life or celibacy, unsatisfactory sexual experiences and negative constructions of their own sexuality due to social ignorance. Leah's response synthesized what she perceived the myth of disability and asexuality to imply.

Leah: The messages we are getting is that you're not sexually attractive; you're not going to get anyone to do that [have sex with you]. You're not going to have someone who is going to love you outside of your family...It's going to affect your social development.

Leah's description of the myth also indicated that these types of messages have an impact on how people with disabilities develop as social and sexual beings. As such, others' perceptions of disability and sexuality were detrimental to participant's socio-sexual development. Of particular concern for Mary was how the myth of disability and asexuality seemed to stem from the misconception that people with physical disability are also intellectually challenged. For example, Mary explained how her transition from a wheelchair and onto crutches after major surgery made the public misunderstanding about disability quite clear.

Mary: Before my big surgery a lot of people would speak to me or to people around me as though they assumed I was intellectually retarded and when you're able enough to understand what's going on, you know, that's part of my issue when I went to school and trying to socialize because you're reticent to put much out there because you know that there's going to be people who are thinking those kind of things.

All of the participants experienced the impact of the myth of disability and asexuality in some form. Notably, a lack 
of societal (public) knowledge about disability was cited as the cause of these experiences.

Leah: No one wants to talk about it because 'people who are disabled don't have sex'. They don't want to address it.

Alex: I think that people should know that being disabled doesn't stop any sexual urge; it doesn't mean that I am asexual.

In addition, Brian, explained that typical others did not "get it" and the impact that societal ignorance had on being considered by others as a sexual partner.

Brian: They just don't get it...it's really a taboo subject, disability and having sex. People with disabilities think that there is no chance for sexual contact with them [typical others]. They [typical others] would think that I'm just not sexually active. If they think I'm not sexy or sexual it makes it difficult to have a relationship with people like that.

As can be seen there are a multitude of messages integral to the myth of disability and asexuality. All participant responses indicated that although they may have wanted to construct their sexuality via other scripts they had internalized the myth in some way, shape or form.

\subsubsection{Internalization of the Myth of Disability and Asexuality}

The internalization of the myth of disability and asexuality was supported by the evidence. The data suggest participants internalized the perception that people with disabilities were and would always be socially and sexually deprived (see also Howland \&Rintala, 2001). For instance, participants explained that satisfying sexual experiences were not going to be a part of the life of someone with a disability because of how sexuality and disability is publically conceptualized. Mary explained how she has observed the myth impact her twin sister who has a more severe form of Cerebral Palsy than herself.

Mary: When you look at someone like my sister, we're both about to turn 25, and the biggest thing in her head is that she will never live independently, she'll never partner, and she'll never be able to have sex or children. But no one talks about that with her. And I'm just saying I'm pretty sure that's what she thinks about - trying to find a partner.

While Mary highlighted the impact of the myth of disability and asexuality she has distanced herself from it by highlighting its effects on others. Similarly, Ian also implied (in reference to his friend who also used a wheelchair) that people with disabilities are privy to fewer sexual options or consideration as sexual partners.

Ian: I mean thank god he was in a wheelchair, because if he wasn't he'd be running after anybody in a skirt, or not in a skirt.

John seemed to agree that sexual opportunities were limited and his chances slim as he was never formally spoken to about sex or sexuality.

John: There was no great sitting down and telling me the facts of life because it wasn't really necessary. I mean when am I going to end up in a situation where I need to be told? Well look, it's always puts me along the lines of being asexual.

For Alex the myth of disability and asexuality made him feel as though he must settle for unsatisfactory sexual encounters if he wanted to experience sexuality with others at all.

Alex: I now don't often equate sex with romance. As much as I have tried to do that in the past, and sometimes currently, I feel that it is not realistic... so now, I take what I can get. I am not happy this way, but I understand it to be the reality of my sexuality.

For these four participants being considered asexual was integral to how they perceived and experienced sexuality with others. Furthermore, participant responses also indicated that having a physical disability went against what was publically expected in order to be perceived as a sexual option for others.

\subsection{Expectations of Normative Movement and Functioning}

Expectations of normative movement and functioning seemed to influence how all the participants' perceived themselves as potential sexual partners for others. Expectations of normative movement and functioning referred to the expectation that the body should, move, function and behave like that of typical bodies. Participants indicated that expectations of normative movement and functioning influenced who they would most be attracted to. As such, participant data fell into the following three sub-themes (see Figure 3): Impact of Expectations of Normative 
Movement and Functioning on Socio-Sexual Development, The Ideal Partner and Perceptions of What is and is Not Physical Disability.

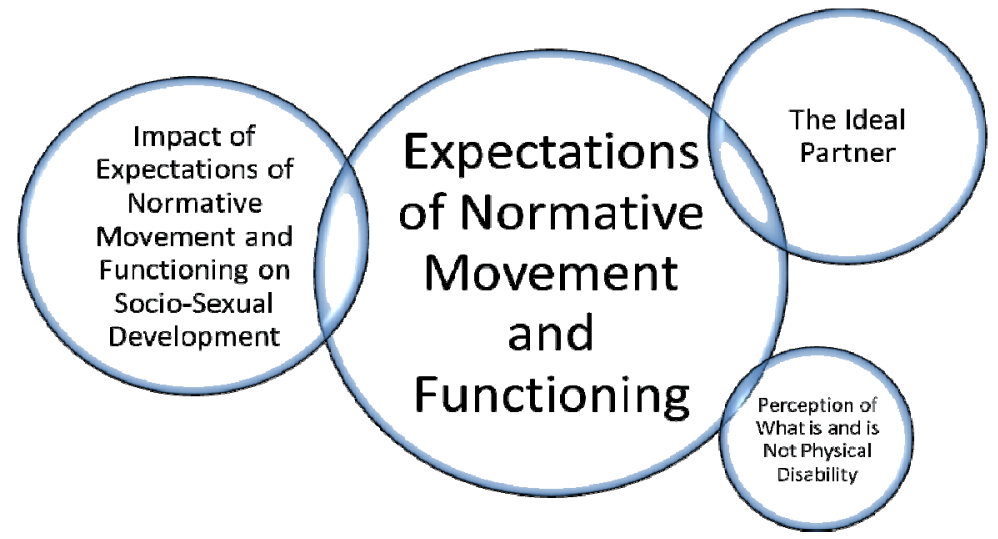

Figure 3. Expectations of Normative Movement and Functioning Theme and Sub-themes

\subsubsection{Impact of Expectations of Normative Movement and Functioning on Socio-Sexual Development}

Participants were of the view that being expected to physically move and function in the same ways as a typical individual created tension within the construction of their sexuality. Participants noted that expectations of normative movement and functioning; 1) affected participation (see also Dune, 2012b), 2) socio-sexual equality (see also Dovidio, Pagotto\&Hebl, 2011) and, 3) implied that physical difference was a socio-sexual "turn-off" to others (see also Dune \&Shuttleworth, 2009). For instance, Alex and Trevor both indicated that living with a physical disability restricted their ability to participate in socio-sexual activities and development.

Alex: My level of mobility also influences my sexuality because I can't perform all of the same functions as an able-bodied person so I often feel inadequate...I feel like I won't find anything long term due to my disability.

Trevor: As I grew older, sexual thoughts developed from 'playing house' into more sexual, or sexually charged, in nature. But, due to my physical limitations, I was not able to fully explore those feelings as early as some people might.

Brian also explained the impact of having to use a wheelchair for mobility on socio-sexual development. Primarily, he indicated that being in a wheelchair meant that he would not be considered as a social or sexual equal because he could not be at eye level with his peers.

Brian: Males are competitive so I mean if I'm after one female and there are three other able-bodied males where is she going to go? I was talking to this girl and there were other guys who walked in and they didn't say 'hello' or anything but they could stand and face her. I was in the room but I might as well not have been there.

The expectation that everyone can or should stand when conversing, particularly in the context of public social venues, made Brian feel that he could not be a social or sexual contender when physically typical men where in the room. John also articulated similar implications of the public expectation to move and function typically:

John: Even around professional colleagues, particularly when you go to a seminar and everybody breaks for morning tea, and usually how that works is everybody stands around a coffee table or a drinks table and has their cakes and biscuits and coffee. Because they're standing and you're sitting it is pretty hard to make it known that you're still there...The problem is, and people don't do it deliberately, everybody has to stand up for conversation and you are immediately on the wrong level to get any tea, coffee, biscuits or a chance.

While John engaged in social activities in order to negotiate relationships not being at eye level made him feel as though he were not and could not build relationships with his peers. Living with a physical disability made it difficult for participants to find opportunities to engage in conversation let alone court. Ultimately some participants felt that living with a disability would be a complete "turn-off" to a potential partner. Ian and John described what they experienced as the realities of living with disability and the effect it would have on a potential partner and sexually intimate relationship.

Ian: ...in a world where we finally got over all our hang ups and we actually do the research and we actually 
make sure that we're not condemning people to disability just so someone can say that we can have a diverse society.

John: I mean the issue really is if you really claim that you really love someone and that you want to spend your life with them under what terms is that mediated...The standard marriage vows go in sickness and in health and that's fine. But it doesn't go in sickness and in constant disease and in constant doctor's appointments and in constant co-morbidities.

The sentiment that impairment was unacceptable or unattractive to potential sexual partners was influenced to how expectations of normative movement and functioning were conceptualized. As such, Ian and John constructed the possibility of finding a suitable partner. As mentioned in the interactional theme Perception of Sexual Experiences with Others, participant's responses indicate that finding an individual to share in the realities of disability with them through understanding and openness was necessary. As such, finding a partner who accepted physical difference was both an interpersonal and public issue. Through the responses however, participants seem to allude to their ideal partner as a physically typical individual, who did not necessarily understand or have experience with impairment.

\subsubsection{The Ideal Partner}

Interestingly all the participants in this study discussed potential partners and previous partners as individuals who were physically typical. As such, participant's ideal partner would; 1) meet public expectations of normative movement and functioning (see also Moin, Duvedevany\&Mazor, 2009) and, 2) be necessary to fulfill care needs and family sustainability (see also Wilder, 2006). For instance, Alex and Brian made it clear that a physically typical partner would be imperative.

Alex: My ideal partner would be able-bodied because I think that having sex with a disabled person is too much work. My ideal partner would be masculine, but extremely open-minded.

Alex blatantly indicated that being with someone who had a disability would not conform to his idea of the perfect partner as they would be "too much work".

Brian: They could walk...yeah, definitely.

For John, a physically typical individual was indicated as necessary in order to fulfill care needs and family sustainability.

John: Well...it would need to be a non-disabled person. Now I don't rule out the other but my concern would be that you're just mounting up the problems for yourselves...I think 20 or 30 years down the track I'm going to be just as sick and just as disabled and just as cranky about all the things I can't do. And then you know somebody else is going to be doing even more.

Based on participant responses the construction of the ideal sexual partner for an individual living with a severe physical disability conformed to expectations of normative movement and functioning. In particular participants indicated that it would difficult to navigate a satisfying sexual relationship with someone who also had a disability. Although Alex, Brian and John indicated that their ideal partner would be physically typical their choice may not have been founded on superficial reasons. As such, participant responses imply that an individual who was physically typical or did not have a moderate to severe impairment could serve as a sort of assistive medium for sexual expression and daily living requirements.

\subsubsection{Perceptions of What is and is Not Physical Disability}

Of the seven participants included in this study Mary (whose twin sister has a severe form of Cerebral Palsy) was the only one who did not use a wheelchair for mobility (after major corrective surgery) but instead relied on crutches some of the time. Mary's experience with physical disability is of interest as she described that in certain situations others perceived her as physically typical. For Mary, this process of being what she perceived as partially typical was consolidated by both public perceptions about disability and interactional encounters with others. As such, Mary explained that living on both sides of the fence (physically typical and atypical) simultaneously proved to be challenging.

I've got a disabled parking permit. But I always get people who shout at me for parking in the parks...I say I've got a sticker and then, you know, sometimes I drag my leg a bit more. Because they look at you! Old people are shocking for it. Like, I haven't been able to walk my entire life, these people end up on a stick at 70, get a parking permit. Get screwed!

For Mary being identified as both an individual with a mild and moderate impairment highlighted the confounding 
aspects the public scripts about physical impairment and public scripts about physical typicality. Mary's experience with disability brings to attention the many barriers that people with mild to moderate Cerebral Palsy face daily. Mary's dichotomous relationship with disability highlights public misunderstandings about atypicality which limits access and therefore restricts social and sexual integration and inclusion.

\subsection{Issues of Accessibility}

Participant believed that access to services, resources, sexual opportunities and the environment in which participants lived also influenced their construction of their sexuality. In this regard, four participants were concerned about the tedious and frustrating experience of trying to navigate structural environments in order to access socio-sexual opportunities. However, three participants indicated that with the help of modern technology they were able to simulate courting and dating online. Finally, one participant indicated that without resources sexually intimate relationships with others were difficult to support for both parties. Participant view fell within three sub-themes (see Figure 4): Structural Access Issues, Access to Sexual Opportunities and Access to Resources which Support Sexually Intimate Relationships.

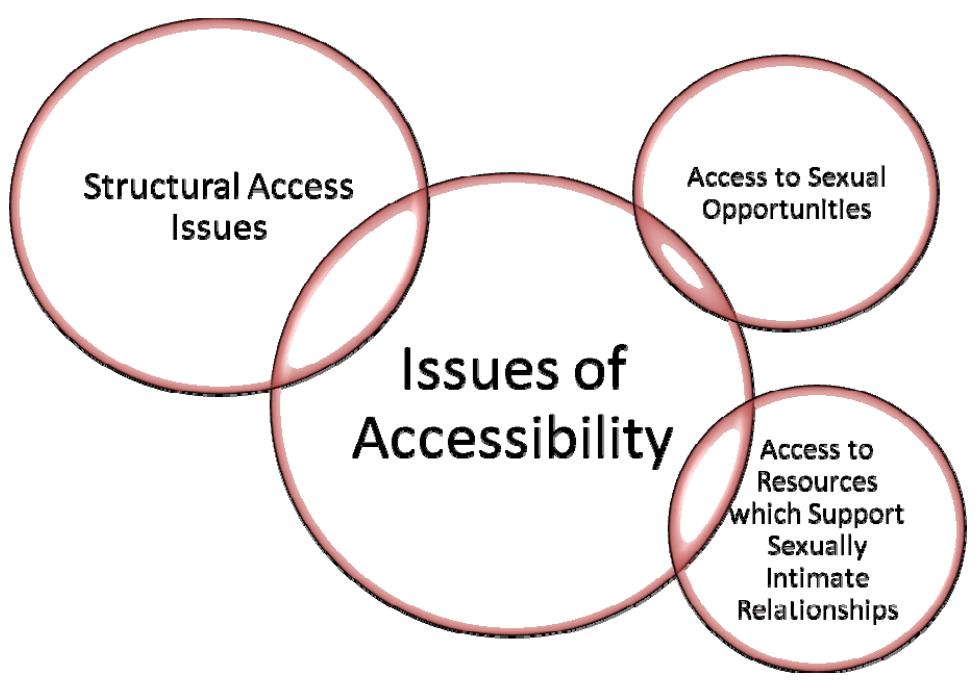

Figure 4. Issues of Accessibility Theme and Sub-themes

\subsubsection{Structural Access Issues}

Participants perceived that accessibility to infrastructure restricted sexual opportunities. Notably, participants perceived that; 1) they spent more time than typical others in the preparation or negotiation of a social outing (see also Yoshida, 1994), 2) infrastructure was generally as accessible as it was inaccessible (see also Rummel, 2009) and, 3) there were ways to bypass structural access issues (see also Jang, Choi \& Lee, 2010). For example, Brian perceived that he had to spend extra time and money when arranging social outings. For him this meant that he had to make more of an effort to access sexual opportunities than his peers:

Brian: It's really frustrating because like I said no one gets it. I think they don't understand what its like to want to do things like everyone else but I can't and I try but there are limits. Wow!! Just stuff like accessibility. I can't go were all the cute girls are going because I can't get in. The extra money I have to spend to do things. It's just difficult so I don't go to those places.

According to John the "extra time" and thought involved in order to organize a date reduced the opportunity to go out spontaneously with friends or a potential sexual partner.

John: Equally, I guess there's the practical point of view. How could I ask someone out? How can we go anywhere every time I go to a lunch? When I went to a lunch or dinner with the office I had to arrange taxis or get mum involved to get me there or to get me back or something like that. So there was always sort of an infrastructure or arrangements that had to be made, unmade or remade to make my attendance somewhere possible. The other factor, it has to be wheelchair accessible doesn't it? So there are immediate questions of, particularly about something being spontaneous, going through all those check points there is nothing spontaneous. 
Brian and John considered many social gathering places as difficult to access; "I can't go were all the cute girls are going because I can't get in" (Brian). However the women acknowledged that there were places that did accommodate people with disabilities. For instance, while Leah felt that negotiating infrastructure (i.e., clubs, pubs, bars, restaurants, etc.) was difficult it could be managed.

Leah: Where do people meet, in bars, restaurants, in cinemas? Again a lot of those places are now accessible but equally a lot of them aren't.

For five of respondents feeling excluded from sexual opportunities was characterized by limited access to public spaces. Alex however, indicated that one does not necessarily need to "go out" to find a sexual partner.

Alex: My sexual history is mostly comprised of casual sexual encounters. I meet the men usually online, because it is difficult for me to get into bars. Most of the men I meet online aren't looking for anything serious though.

Although Alex felt that he may not get a chance to foster a long term relationship from his interactions on the internet he highlights an innovative portal for access to sexual opportunities.

\subsubsection{Access to Sexual Opportunities}

For some participants going online was a viable alternative to trying to navigate infrastructure which was not guaranteed to be accessible. This was primarily exemplified through being virtually available via the internet and being physically present at social venues and outings (see also Holden, 2006). Sexual opportunities were also accessed through the employment of sex workers (see also Sanders, 2007). For Mary a conjunction of physically "getting out there" and using the internet helped increase her chances when she met her boyfriend.

Mary: I think probably getting out there and going out to places and being seen and doing stuff. Maybe also the internet. Seeing what's out there you know.

Brian also felt that navigating the virtual world of internet dating proved to be less frustrating and more liberating than being out in the real world.

Brian: You just go online really. And I have several girls on my list and the virtual world gives me the chance to act out ideas or fantasies that I would like to experience. It's a lot of fun but it's frustrating... if someone doesn't like that. But I stay hopeful, like anyone else and just keep going.

For Ian the opportunity to be with someone sexually was all he really wanted.

Ian: In my experience it's probably just the opportunity to have sex which makes it good. When I get an erection from someone touching my penis. Being able to experience my sexuality is the best part.

All participants perceived that it was difficult to access sexual opportunities due to structural restrictions; "I meet the men usually online, because it is difficult for me to get into bars" (Alex) or low levels of peer-receptiveness; "It's a lot of fun but it's frustrating... if someone doesn't like that" (Brian). To alleviate some of the social and structural issues Brian, for instance, employed the services of a sex worker:

Investigator: Which was your best experience?

Brian: The one in Melbourne. It's called the "[name of Gentleman's Club]"

Investigator: ... Why was that your best experience?

Brian: Well I got there and went to the room and it was a proper place. There was several rooms. And I had time with a dancer.

Investigator: So you got your own private dance? Anything else happen?

Brian: Oh yeah. I went to touch her and I thought I couldn't touch her. I spent quite a bit of money on her.

Investigator: Was it just dancing?

Brian: I spent a bit of money on her. So you can imagine.

Investigator: Have you been to any brothels?

Brian: No, not yet.

Investigator: Do you want to go?

Brian: At some stage yeah.

Investigator: So your best sexual experience was someone who talked with you, danced for you and kinda just 
played with you and was cheeky.

Brian: Yeah.

Investigator: So there wasn't anything overtly sexual in terms of touching or anything...

Brian: Well you know...

Investigator: That's cool.

Brian: YEAH! IT WAS! [participant's emphasis]

Facilitation of sexual services (as provided by a sex worker in Australia) helped Brian bridge access to sexual encounters. In doing so, he may be privy to experiencing and constructing his own sexuality without the social or structural restrictions some of the other participants indicated. While Canadian participants could not legally have explored their sexuality through the employment of a sex worker they did indicate that public access to resources which can support sexually intimate relationships were necessary.

\subsubsection{Access to Resources which Support Sexually Intimate Relationships}

The lack of resources which allow people with disabilities to enjoy long-term sexually intimate relationships was confounding to participant's construction of themselves as potential sexual partners (Kitchin, 2002). For instance, Ian felt by others not wanting to facilitate sexual activity between people with disabilities restricted his sexual expression.

Ian: I would have liked to [have sex] yeah but we just went to the bedroom and tried to get in there but we just ended up having a bit of a pash ["making out"] and a cuddle. I would have liked to [have sex] because at that time there was an attendant around they could have helped us but thought it was weird.

For John the practicalities of life with a disability made him feel skeptical about opportunities to access a long-term sexually intimate partner.

John: Let's just theorize for a moment. That other partner or person would end up with a great deal of the economic responsibility purely for the reason that employers will look at somebody with a disability and say 'well yes we could tick a diversity box but we don't want all the red tape that goes along with it' and you know, that's a half reasonable economical decision to make. Particularly if you believe you are going to have to file a lot of forms, get a lot of approvals, and it's going to cost you to adjust the workplace, and if you're a small or even a medium or even sometimes a big business you wonder whether that is an appropriate use of your resources.

For all participants accessibility proved to be an issue when trying to negotiate sexual opportunities. Not being able to engage in sexual activities or express one's sexuality had an impact on how people within the study constructed themselves and their bodies as sexual. In this regard, the consolidation of interactional and public sexual schema by the informants of this study was reinforced by private constructions of themselves and their sexuality.

\section{Limitations}

This study had some limitations; 1) cultural homogeneity, 2) restrictions of qualitative methodology, and 3) constraints of script theory. First, the cultural frame was homogenous. Namely all the participants in this study were Caucasian, from developed nations, had completed post-secondary education and were within the spectrum of middle class socio-economic status. Limited cultural and linguistic diversity (CALD) (Rao, Warburton \& Bartlett, 2006) may have skewed the findings. Research which includes a more culturally, ethnically and financially diverse sample is needed in order to determine whether these points of diversify would have an impact on the findings of this study.

Second, the qualitative methodology used within this study allowed for rich descriptive and contextual information. Interpretive inquiry allows for some data contours to be emphasized more than others (Mayoux, 2006). For instance, the data collected is mediated by the investigator's ability to ask questions or probe answers which allowed respondent's to comprehensively articulate their concepts, conceptualizations and conceptions of sexuality with disability. In doing so respondents may have found it easier to express some or certain sexual schema and not others due to their abstract nature or convolutions within the questions. Research which explores constructions of sexuality with Cerebral Palsy using different qualitative techniques (i.e., focus groups, case studies and observations) would further clarify the findings of this study.

Finally, sexual script theory was the theoretical basis for this research. Sexual script theory however, delineates sexual influences into public, interactional and private sexual schema. However, the findings of this study emphasize 
that people with Cerebral Palsy are agents in the construction of their sexuality. Bandura's social cognitive theory (1986, 1997, 2006), which highlights people as social agents, may therefore be a better theory to apply to constructions of sexuality with Cerebral Palsy. Research which employs Bandura's social cognitive theory and constructions of sexual with disability would be beneficial to further understanding agency and sexuality with disability.

\section{Conclusion}

This study sought to investigate, understand and to develop existing knowledge and theory on how people with cerebral palsy constructed their sexuality. Bringing to attention discussions on both sexual agency and being, this study found that constructions of sexuality with cerebral palsy are influenced by public sexual schema. It also highlights the role of people with cerebral palsy in the interpretation of those scripts and their manifestations. Ultimately, this study emphasizes that people with cerebral palsy are cognizant, intelligent about their sexuality the factors which influence its constructions. In particular, their conceptualisations and descriptions of their sexuality speak to their interest and awareness about key issues related to it.

In the recent past constructions of sexuality were often defined by healthcare institutions and providers, educational institutions, religious organizations, parents, families and peers adoption of an "ignorance is bliss" attitude to discussing, educating or advocating sexual activity for wellbeing for people with disabilities (Tepper, 2000). This lack of discussion concerning sexual expression and disability often stemmed from restrictions on the accessibility of comprehensive sexual information. Without inclusion in public discourses and popular culture people with cerebral palsy, as well as other disabilities, may find it particularly difficult to accept themselves as complete sexual beings and their ability to be an exciting and desirable sexual partner. While this may presently be the case people with disabilities do experience and explore the many facets and potential faces of their sexuality.More about how they successfully do so requires exploration and dissemination amongst people with disabilities, disability advocates and the general public in order to support sexual wellbeing and agency.

\section{References}

Anderson, P., \& Kitchin, R. (2000). Disability, space and sexuality: access to family planning services. Social Science and Medicine, 51, 1163-1174. http://dx.doi.org/10.1016/S0277-9536(00)00019-8

Bandura, A. (1986). Social foundations of thought and action: A social cognitive theory. Englewood Cliffs: Prentice-Hall.

Bandura, A. (1997). Self-efficacy: The exercise of control. New York: 1997. http://dx.doi.org/10.1016/0149-7189(90)90004-G

Bandura, A. (2006). Guide for constructing self-efficacy scales. In F. Pajares, \& T. C. Urdan, Self-efficacy beliefs of adolescents (pp. 307-338). Charlotte: Information Age Publishing.

Barber, K., Berger, A., Ricci, C., Sperling, A., \& Yerxa, R. (Producers). (2002). Pumpkin [Motion Picture]. United States.

Barnes, C., \& Mercer, G. (2010). Exploring disability. Cambridge: Polity.

Baudrillard, J. (1983). Simulations. New York: Semiotext(e).

Berman, H., Harris, D., Enright, R., Gilpin, M., Cathers, T., \& Bukovy, G. (1999). Sexuality and the adolescent with a physical disability: understandings and misunderstandings. Issues in Comprehensive Pediatric Nursing, 22(4), 183-196.

Brown, D. E. (1988). Factors affecting psychosexual development of adults with congenital physical disabilities. Physical \& Occupational Therapy in Pediatrics, 8(2-3), 43-58. http://dx.doi.org/10.1080/J006v08n02_03

Brown, J. D., Halpern, C. T., \& L'Engle, K. L. (2005). Mass media as a sexual super peer for early maturing girls. Journal of Adolescent Health, 36(5), 420-427. http://dx.doi.org/10.1016/j.jadohealth.2004.06.003

Bryce, I., DeSanto, T., Bonaventura, L. d., \& Murphy, D. (Producers). (2007). Transformers [Motion Picture]. United States.

Chance, R. S. (2002). To Love and Be Loved: Sexuality and People with Physical Disabilities. Journal of Psychology and Theology, 30.

Cole, S. S., \& Cole, T. M. (1993). Sexuality, disability, and reproductive issues through the lifespan. Sexuality and Disability, 11(3), 189-205. http://dx.doi.org/10.1007/BF01102578 
Corker, M., \& French, S. (1999). Disability discourse. New York: Open University Press.

Corker, M., \& Shakespeare, T. (2002). Disability/postmodernity: Embodying disability theory. London: Continuum International Publishing Group.

Crewe, N. M. (1979). The psychologist's role in sexual rehabilitation of people with physical disabilities. Sexuality and Disability, 2(1), 16-22. http://dx.doi.org/10.1007/BF01101075

Dovidio, J. F., Pagotto, L., \& Hebl, M. R. (2011). Implicit Attitudes and Discrimination Against People with Physical Disabilities. Disability and Aging Discrimination, Part 2, 157-183. http://dx.doi.org/10.1007/978-1-4419-6293-5_9

Duncan, K., Goggin, G., \& Newell, C. (2005). Don't talk about me... like I'm not here: Disability in Australian national cinema. Metro Magazine: Media \& Education Magazine, 146/147, 152-159.

Dune, T. (2012b). Sexual expression, fulfilment and haemophilia: Reflections from the 16th Australian and New Zealand Haemophilia Conference. Haemophilia, published online. http://dx.doi.org/10.1111/j.1365-2516.2011.02743.x

Dune, T. M. (2012a). Constructions of Sexuality and Disability: Implications for People with Cerebral Palsy. Saarbrücken: Lambert Academic Publishing.

Dune, T. M., \& Shuttleworth, R. P. (2009). "It's Just Supposed to Happen": The Myth of Sexual Spontaneity and the Sexually Marginalized. Sexuality and Disability, 27(2), 97-108. http://dx.doi.org/10.1007/s11195-009-9119-y

Earle, S. (1999). Facilitated sex and the concept of sexual need: disabled students and their personal assistants. Disability and Society, 14, 309-323. http://dx.doi.org/10.1080/09687599926163

Esibill, N. (1980). Sexuality and disability: A model for short term training. Sexuality and Disability, 3(2), 79-83. http://dx.doi.org/10.1007/BF01101058

Goggin, G., \& Newell, C. (2002). Digital Disability: The Social Construction of Disability in New Media (Critical Media Studies: Institutions, Politics \& Culture Series). Lanham: Rowman \& Littlefield.

Guildin, A. (2000). Self-Claiming Sexuality: Mobility Impaired People and American Culture. Sexuality and Disability, 18(4), 233-238.

Hammar, G. S., Ozolins, A., Idvall, E., \& Rudebeck, C. E. (2009). Body image in adolescents with cerebral palsy. Journal of Child Health Care, 13(1), 19-29. http://dx.doi.org/10.1177/1367493508098378

Hartnett, A. (2000). Escaping the 'Evil Avenger' and the 'Supercrip': images of disability in popular television. Irish Communications Review, 8, 21-29.

Holden, C. (2006). Just Getting on with It: A Record of Service About Relationships and Disability. Social Work with Groups, 29-44. http://dx.doi.org/10.1300/J009v30n01_05

Howland, C. A., \& Rintala, D. H. (2001). Dating Behaviours of Women with Physical Disabilities. Sexuality and Disability, 19(1), 41-70.

Jackson, S. (2005). 'Dear Girlfriend...': Constructions of Sexual Health Problems and Sexual Identities in Letters to a Teenage Magazine. Sexualities, 8(3), 282-305. http://dx.doi.org/10.1177/1363460705049577

Jang, M., Choi, J., \& Lee, S. (2010). A customized mouse for people with physical disabilities. ASSETS '10 Proceedings of the 12th international ACM SIGACCESS conference on Computers and accessibility. New York: ACM Digital Library. http://dx.doi.org/10.1145/1878803.1878871

Joseph, R. (1991). A case analysis in human sexuality: Counseling to a man with severe cerebral palsy. Sexuality and Disability, 9(2), 149-159. http://dx.doi.org/10.1007/BF01101740

Katzenberg, D., \& Grahame-Smith, S. (Producers). (2010). The Hard Times of RJ Berger [Motion Picture]. United States.

Law Commission. (1995). Mental Incapacity: A Summary of the Law Commission's Recommendations (LC231). London: Stationary Office.

Lemish, D. (2010). Screening gender on children's television: the views of producers around the world. London: Taylor \& Francis.

Lipkin, D., Burson, C., Payne, A., Rosenberg, M., Halpern, N., \& Morayniss, J. (Producers). (2010). Hung [Motion Picture]. United States. 
Majiet, S. (1996). Sexuality and Disability. Agenda, 28, 77-80. http://dx.doi.org/10.2307/4065761

Mayoux, L. (2006). Quantitative, qualitative or participatory? which method, for what and when. In V. Desai, \& R. B. Potter, Doing development research (pp. 113-129). London: Sage.

McCabe, M., \& Taleporos, G. (2003). Sexual esteem, sexual satisfaction, and sexual behavior among people with physical disability. Archives of Sexual Behaviour, 32, 359-369.

Milligan, M. S., \& Neufeldt, A. H. (2001). The Myth of Asexuality: A Survey of Social and Empirical Evidence. Sexuality and Disability, 19(2), 91-109.

Moin, V., Duvdevany, I., \& Mazor, D. (2009). Sexual Identity, Body Image and Life Satisfaction Among Women With and Without Physical Disability. Sexuality and Disability, 27(2), 83-95. http://dx.doi.org/10.1007/s11195-009-9112-5

Murphy, K. P., Molnar, G. E., \& Lankasky, K. (2000). Employment and social issues in adults with cerebral palsy. Archives of Physical Medicine and Rehabilitation, 81(6), 807-811. http://dx.doi.org/10.1053/apmr.2000.6798

Oliver, M. (1996). Understanding disability: From theory to practice. Basingstoke: Palgrave Macmillan.

Overstreet, L. C. (2008). Splitting sexuality and disability: A content analysis and case study of internet pornography featuring a female wheelchair user. Sociology Theses.

ParaQuad. (2010). Personal Care. Retrieved October 26th, 2010, from http://www.paraquad.org.au/CommunityServices/PersonalCare.aspx

Pendo, E. (2010). A Service Learning Project: Disability, Access and Health Care. Journal of Law, Medicine and Ethics, 28, 2010-2013. http://dx.doi.org/10.1111/j.1748-720X.2010.00476.x

Rao, D. V., Warburton, J., \& Bartlett, H. (2006). Health and social needs of older Australians from culturally and linguistically diverse backgrounds: issues and implications. Australasian Journal on Ageing, 25(4), 174-179. http://dx.doi.org/10.1111/j.1741-6612.2006.00181.x

Raynor, O., \& Hayward, K. (2009). Breaking into the business: experiences of actors with disabilities in the entertainment industry. Journal of Research in Special Educational Needs, 9(1), 39-47. http://dx.doi.org/10.1111\%2Fj.1471-3802.2009.01114.x

Ross, E., \& Rapp, R. (1981). Sex and society: a research note from social history and anthropology. Comparative Studies in Society and History, 23(1), 51-72. http://dx.doi.org/10.1017/S0010417500009683

Rousso, H. (1993). Special considerations in counseling clients with cerebral palsy. Sexuality and Disability, 11(1), 99-108. http://dx.doi.org/10.1007/BF01102311

Rummel, A. M. (2008). Travel by people with physical disabilities: A diffusion study focused on opinion leadership. Detroit: Michigan State University.

Salsano, S., Jeffress, S., \& French, J. (Producers). (2010). Jersey Shore [Motion Picture]. United States.

Sanders, T. (2007). The politics of sexual citizenship: commercial sex and disability. Disability and Society, 22(5), 439-455. http://dx.doi.org/10.1080/09687590701427479

Sanders, T. (2008). Male Sexual Scripts: Intimacy, Sexuality and Pleasure in the Purchase of Commercial Sex. Sociology, 42(3), 400-417.http://dx.doi.org/10.1177/0038038508088833

Schillmeier, M. (2007). Dis/abling spaces of calculation: blindness and money in everyday life. Environment and Planning D., 25, 594-609. http://dx.doi.org/10.1068/d4173

Shakespeare, T. (2000). Disabled sexuality: toward rights and recognition. Sexuality and Disability, 18(3), 159-166.

Simon, W., \& Gagnon, J. H. (1986). Sexual scripts: Permanence and change. Archives of Sexual Behaviour, 15(2), 97-120. http://dx.doi.org/10.1007/BF01542219

Simon, W., \& Gagnon, J. H. (1987). A sexual scripts approach. In J. H. Geer, \& W. T. O'Donohue, Theories of human sexuality (pp. 363-383). London: Plenum Press.

Simon, W., \& Gagnon, J. H. (2003). Sexual scripts: Origins, influences and changes. Qualitative Sociology, 26(4), 491-497. http://dx.doi.org/10.1023/B:QUAS.0000005053.99846.e5 
Stevens, E., Steele, C. A., Jutai, J. W., Kalnins, I. V., Bortolussi, J. A., \& Biggar, D. (1996). Adolescents with physical disabilities: Some psychosocial aspects of health. Journal of Adolescent Health, 19(2), 157-164. http://dx.doi.org/10.1016/1054-139X(96)00027-4

Taleporos, G., \& M, M. (2001). Physical disability and sexual esteem. Sexuality and Disability, 19, 131-148.

Taleporos, G., \& McCabe, M. (2005). The relationship between the severity and duration of physical disability and body esteem. Psychology and Health, 20(5), 637-650. http://dx.doi.org/10.1080/0887044042000334733

Tepper, M. S. (1999). Letting Go of Restrictive Notions of Manhood: Male Sexuality, Disability and Chronic Illness. Sexuality and Disability, 17(1), 37-52.

Tepper, M. S. (2000). Sexuality and disability: The missing discourse of pleasure. Sexuality and Disability, 18(4), 283-290.

Wilder, E. I. (2006). Wheeling and dealing: living with spinal cord injury. Nashville: Vanderbilt University Press.

Winkler, D., Sloan, S., \& Callaway, L. (2007). Younger People in Residential Aged Care: Support needs, preferences and future directions. Brentford Square: Summer Foundation.

Wiwanitkit, V. (2008). Sexuality and Rehabilitation for Individuals with Cerebral Palsy. Sexuality and Disability, 26(3), 175-177. http://dx.doi.org/10.1007/s11195-008-9088-6

Woodall, A. M., Novick, M., \& Silverstein, K. (Producers). (2010). Glee [Motion Picture]. Los Angeles.

World Health Organization. (2011). Disabilitites. Retrieved February 18th, 2011, from http://www.who.int/topics/disabilities/en/

Xenakis, N., \& Goldberg, J. (2010). The Young Women's Program: A health and wellness model to empower adolescents with physical disabilities. Disability and Health Journal, 3(2), 125-129. http://dx.doi.org/10.1016/j.dhjo.2009.08.001

Yoshida, K. K. (1994). Intimate and Marital Relationships: An Insider's Perspective. Sexuality and Disabiltiy, 12(3), 179-189. http://dx.doi.org/10.1007/BF02547904 